\title{
Measurement and spatial difference of agricultural green development level in Guangxi
}

\author{
Quan Qin \\ Guangxi Normal University, Guilin, 541004, China
}

*Corresponding e-mail: 214239164@qq.com

ARTICLE INFO

Article History

Received 3 September 2021

Revised 22 November 2021

Accepted 22 November 2021

\section{Keywords}

Green development of

agriculture;

Entropy method;

Difference analysis.

How to cite this article: Qin, Q. (2021). Measurement and spatial difference of agricultural green development level in Guangxi. Bulletin of Applied Mathematics and Mathematics Education, 1(2), 93-104.

\section{ABSTRACT}

Green development of agriculture is the foundation of the entire green development. As a big agricultural province, promoting the green development of agriculture is conducive to promoting the high-quality development of agriculture and rural revitalization in Guangxi. This paper firstly analyzes the domestic and foreign scholars' research on the green development of agriculture, combined with the relevant policy theory, constructs the index system from the three aspects of green production, economic benefits and living standards, and then uses the entropy method to calculate the index weight and the comprehensive score of the green development of Agriculture in Guangxi, it analyzes the development trend of agricultural green development in Guangxi from 2010 to 2019 and the spatial differences of agricultural green development in 14 cities of Guangxi in 2019 afterwards. Finally, the following conclusions are drawn: the agricultural green development in Guangxi is on the rise from 2010 to 2019, but the development of green production is still in stagnancy; the overall level of Guangxi's agricultural green development in 2019 is relatively low, the best comprehensive developed cities are Guilin and Yulin, while the Hechi got the worst comprehensive score. According to the above conclusion, Guangxi should increase investment in science and technology to promote green agricultural production, focus on the overall development of the city to achieve regional coordination, give full play to the linkage effect of the city, and encourage well-developed cities to drive the development of surrounding cities.

This is an open access article under the CC-BY-SA license.

\section{(ㅇ) (1) (-)}

\section{Introduction}

Guangxi is one of the top ten agricultural provinces in China. It is located in the subtropical monsoon climate zone. Therefore, the warm climate, abundant heat and precipitation provide an excellent production condition for Guangxi's agricultural development. However, in recent years, there have been many problems in the development of green agriculture in Guangxi, such as weak agricultural production infrastructure and low mechanization. Hence, this article takes Guangxi as the research object and explores Guangxi's agricultural green development status. improving the 
effective utilization of agricultural resources in Guangxi, promoting the modernization, sustainable and high-quality development of Guangxi's agriculture, improving the level of green agricultural development, improving the lives of farmers, and promoting Rural development.

Research on the green development of agriculture is relatively early in foreign countries. In the early days, the United States first proposed ecological agriculture and established research institutes to conduct related research. Lockeretz (1989) conducted research on ecological agriculture and found many important problems in it, and conducted in-depth exploration. With the development of industrialization, environmental problems have become more and more serious. Countries such as France, the United Kingdom, Japan, and the Philippines have raised green agriculture development and formulated development policies.

Domestic research on green agricultural development started relatively late, and most of the research was concentrated in 2017-2020. The research is mostly based on theoretical research and development model research, while quantitative analysis research is rare. Chenghao (2017), from the perspective of input and output, established an indicator system from the four aspects of green development economy, input, utilization and safety, and used the entropy method to carry out a comprehensive weighted score, and analyzed the national agricultural green development. Regional differences; Lina and Guiying (2018) built an indicator system from the perspectives of economy, environment, and life to reflect the three aspects of the impact of agricultural green production, and used the entropy method to carry out a weighted comprehensive score to analyze the changes and influencing factors of agricultural green development in Ningxia. Saimei (2019) considered the causal relationship between human activities and the environment, used the DPSIR model to construct an indicator system from seven aspects, used the entropy method to perform a weighted comprehensive score, and used Theil index to analyze regional differences. Yao et al. (2020) constructed an indicator system from three aspects: economic efficiency, green production, and integrated development, used the entropy TOPSIS method to perform weighted comprehensive scoring, and analyzed the dynamic development changes and regional differences in Shaanxi Province. Jianjie and Shilei (2020) are based on the "production, processing, and consumption" system, constructing an indicator system around the three dimensions of society, economy, and ecological environment. They apply this system to carry out relevant explanations and verification.

In summary, most domestic scholars have little research on agricultural green development, and there are very few researches on the quantitative analysis of agricultural green development in Guangxi. Zhuangli and Jing (2016) constructed Guangxi agricultural green development indicators system, but they did not conduct a specific analysis. There is no complete and comprehensive quantitative research on the green development of agriculture in Guangxi, it's meaningful that this article analyzes the trends and differences of the green development of agriculture in Guangxi.

This paper takes Guangxi and 14 cities in Guangxi as the research objects. The study of relevant documents and policies constructs a Guangxi agricultural green development indicator system containing 12 indicators from three aspects: green production, economic benefits, and living standards, and collects relevant information. This paper uses the entropy method of objective weighting to calculate the index weight and the final evaluation score. This article uses calculation results to analyze the data from two dimensions. From the time dimension, this article calculates the score of Guangxi's agricultural green development from 2010 to 2019, and analyzes its overall development trend in the past 10 years. from the spatial dimension, using 2019 as the analysis section, it calculates the agriculture of the 14 cities in Guangxi in 2019 Green 
development scores, gets the development rankings of 14 cities. more intuitively explores the spatial differences in the green development of agriculture in Guangxi, and finally puts forward reasonable suggestions.

\section{Method}

Since the 18th National Congress of the Communist Party of China, realizing the green development of agriculture is an important task for promoting rural revitalization. Guangxi is a large agricultural province, and it is of great significance to analyze the green development of agriculture in Guangxi. To evaluate the green development of agriculture in Guangxi, we must first build a suitable indicator system for the green development of agriculture in Guangxi. The establishment of the indicator system determines the effectiveness of the evaluation work. In addition, according to the characteristics and needs of the data, choosing an evaluation measurement method also plays an important role.

\section{Index system construction and measurement principles}

This article measures and calculates the green development of agriculture by constructing an index system. How to process the data and choose the appropriate index has an important influence on the evaluation result. This article constructs the following three principles [8], and establishes the Guangxi agricultural green development evaluation index system strictly following these principles.

\section{Scientific principle}

The indicator data should be obtained from the official website, and the standardized processing and calculation of the data should follow the scientific principle. Secondly, the response layer and the selected indicators should be built around the green development of agriculture.

\section{Representativeness principle}

The construction of the indicator system should comprehensively consider the interrelated factors of agricultural production, the economic benefits of output and the impact on farmers' lives, and build a multi-angle and comprehensive response layer. Secondly, the selected indicators should reflect the response layer to the greatest extent, and the indicators should be as few and precise as possible.

\section{Operability principle}

The selected index has a clear concept and can be quantitatively analyzed. Secondly, the selected indicator data should be available and easy to calculate, and it is better to discard indicators that are difficult to obtain and calculate.

\section{Index system establishment}

According to the ideas and construction principles of the indicator system, we can establish an index system with three response layers which are green production, economic benefit and living standard respectively. These corresponding layers contain a total of 12 indicators. The green production response layer contains 5 indicators: Fertilizer use intensity、 Irrigation water usage intensity、Total mechanical power per unit area、Forest cover rate and Sewage treatment rate, expressed by $X_{1} 、 X_{2} 、 X_{3} 、 X_{4} 、 X_{5}$ respectively. The economic benefit response layer contains 4 indicators: gross agricultural output value per unit area voutput of grain crops per unit 
area.

Agricultural output value as a percentage of GDP、 per capita agricultural output value, expressed by $X_{6} 、 X_{7} 、 X_{8} 、 X_{9}$ respectively. The living standard response layer contains 3 indicators: per capita disposable income of rural residents 、rural per capita living consumption expenditure 、 rural housing area per capita, expressed by $X_{10} 、 X_{11} 、 X_{12}$ respectively.

The purpose of this paper is to analyze the green development trend of agriculture in Guangxi and the green development differences of 14 cities in Guangxi. Therefore, we collect relevant indicator data in Guangxi from 2010 to 2019. The above indicator data are derived from the "Guangxi Statistical Yearbook", "China Statistical Yearbook" and "China City Statistical Yearbook". The statistical caliber is consistent, which ensures the availability and reliability of the data. Due to the lack of individual data from 2010 to 2019, this article fills in by searching the statistical bulletins of localities and cities and using adjacent average values.

\section{Index system weight establishment and evaluation model}

The method of establishing index weight mainly includes the objective weighting method and subjective weighting method. The subjective empowerment method is based on the subjective scoring of experts, which is easy to be influenced by subjective thinking. The objective weighting law uses mathematical methods to calculate and determine the weights based on the relationship between the original data. It is not easily affected by human subjective factors and is supported by mathematical theoretical foundations. The entropy method is a weighting method in the objective weighting method, which judges the weight according to the degree of dispersion of the index data. The greater the calculated entropy value, the greater the degree of dispersion of the index. The greater the impact of this index on the evaluation, the greater the weight. This paper selects the entropy method in the objective weighting method to establish the index weight. The basic steps are as follows:

\section{Establish an initial data structure}

Assuming that the number of samples is $m$ and the number of indicators selected is $n$, an initial data matrix is constructed as:

$$
X=\left[\begin{array}{cccc}
x_{11} & x_{12} & \ldots & x_{1 n} \\
x_{21} & x_{22} & \ldots & x_{2 n} \\
\ldots & \ldots & \ldots & \ldots \\
x_{m 1} & x_{m 2} & \ldots & x_{m n}
\end{array}\right]
$$

Abbreviated as $\left[x_{i j}\right]_{m \times n}$, where $1 \leq \mathrm{i} \leq \mathrm{m}, 1 \leq \mathrm{j} \leq \mathrm{n}, x_{i j}$ Represents the $\mathrm{j}$-th index value of the i-th sample.

\section{Standardization of original data}

Due to the difference in measurement units and positive and negative attributes between the indicators, there is no comparability between the data. The original data cannot be used for direct analysis. Therefore, the original data needs to be standardized. According to the characteristics of the data, this paper does not have a large range, so the range method is selected to process the original data.

The positive index range processing formula:

$$
\mathrm{x}_{\mathrm{ij}}=\mathrm{x}_{\mathrm{ij}}-\min \left\{\mathrm{x}_{\mathrm{ij}}\right\} / \max \left\{\mathrm{x}_{\mathrm{ij}}\right\}-\operatorname{minx}_{\mathrm{ij}}
$$


The negative index range processing formula:

$$
\mathrm{x}_{\mathrm{ij}}=\max \left\{\mathrm{x}_{\mathrm{ij}}\right\}-\mathrm{x}_{\mathrm{ij}}{ }^{\prime} / \max \left\{\mathrm{x}_{\mathrm{ij}}\right\}-\operatorname{minx}_{\mathrm{ij}}
$$

Finally, get the standard matrix after polarization

$$
\mathrm{X}=\mathrm{x}_{\mathrm{ij}}{ }^{\prime} \mathrm{m} \times \mathrm{n}
$$

Calculate the proportion of the index

According to the standardized data, the proportion of the calculated index is:

$$
y_{i j}=\frac{x_{i j}}{\sum_{i=1}^{m} x_{i j}}
$$

Where $0 \leq \mathrm{y}_{\mathrm{ij}} \leq 1$, it gives the matrix $\mathrm{Y}=\left[\mathrm{y}_{\mathrm{ij}}\right]_{\mathrm{m} \times \mathrm{n}}$.

Calculate the information entropy of the index

$$
e_{j}=-k \sum_{i=1}^{m} y_{i j} \ln y_{i j}
$$

Where $\mathrm{i} \leq \mathrm{e}_{\mathrm{ij}} \leq \mathrm{j}, \mathrm{k}=1 / \ln \mathrm{m}, \mathrm{m}$ is the number of samples. Note: Since $\mathrm{y}_{\mathrm{ij}}=0, \ln \mathrm{y}_{\mathrm{ij}}$ is not defined, the overall matrix $Y$ is shifted 0.0001 units to the right, that is, 0.0001 is added to each value in the matrix.

Calculate the coefficient of difference

$$
g_{j}=1-e_{j}
$$

The greater the difference in the index value of the $\mathrm{j}$-th index, that is, the greater the value of $g_{j}$, the greater its impact on the evaluation.

Calculate the index weight

$$
w_{i j}=\frac{g_{j}}{\sum_{j=1}^{n} g_{j}}
$$

Calculate the comprehensive evaluation value

$$
F_{i}=\sum_{j=1}^{n} x_{i j} w_{j}
$$

Through the comprehensive weighted calculation of $\mathrm{w}_{\mathrm{j}}$, the comprehensive evaluation value of the i sample can be finally obtained. The larger the comprehensive evaluation value, the better the development of the sample.

\section{Results and Discussion}

\section{Analysis on the trend of agricultural green development level measurement}

\section{Calculation result}

This article collects the indicator data of Guangxi from 2010 to 2019, calculates the level of Guangxi's agricultural green development from 2010 to 2019, and analyzes its development trend. First, establish an initial data matrix and use the above entropy method to calculate the level of green agricultural development in Guangxi from 2010 to 2019. The specific calculation results are shown in Table 1. 
BAMME Vol. 1 No. 2, October 2021, pp. 93-104

Table 1. 2010-2019 Guangxi agricultural green development index weight calculation results

\begin{tabular}{cccccc}
\hline $\begin{array}{c}\text { Response } \\
\text { layer }\end{array}$ & $\begin{array}{c}\text { Indicator } \\
\text { variable }\end{array}$ & $e_{j}$ & $g_{j}$ & $w_{j}$ & $F_{i}$ \\
\hline Green & $X_{1}$ & 0.8907 & 0.1093 & 0.0964 & 0.3289 \\
production & $X_{2}$ & 0.9219 & 0.0781 & 0.0689 & \\
& $X_{3}$ & 0.9174 & 0.0826 & 0.0728 & \\
& $X_{4}$ & 0.9489 & 0.0511 & 0.0451 & \\
Economic & $X_{5}$ & 0.9482 & 0.0518 & 0.0457 & \\
benefit & $X_{6}$ & 0.8912 & 0.1088 & 0.0959 & 0.3485 \\
& $X_{7}$ & 0.9121 & 0.0879 & 0.0775 & \\
& $X_{8}$ & 0.9111 & 0.0889 & 0.0784 & \\
Standard of & $X_{9}$ & 0.8903 & 0.1097 & 0.0967 & \\
living & $X_{10}$ & 0.8727 & 0.1273 & 0.1122 & 0.3226 \\
& $X_{11}$ & 0.8782 & 0.1218 & 0.1074 & \\
& $X_{12}$ & 0.8832 & 0.1168 & 0.1030 & \\
\hline
\end{tabular}

According to the calculated index weight results, the matrix $X^{\prime}=\left[\mathrm{x}_{\mathrm{ij}}^{\prime}\right]_{14 \times 12}$ calculated by the entropy method is used for comprehensive weighting calculation to obtain the final score of Guangxi's agricultural green development level from 2010 to 2019, as shown in Table 2.

Table 2. 2010-2019 Guangxi agricultural green development score

\begin{tabular}{ccccc}
\hline Year & $\begin{array}{c}\text { Green } \\
\text { production }\end{array}$ & $\begin{array}{c}\text { Economic } \\
\text { benefit }\end{array}$ & Living standard & Comprehensive \\
\hline 2010 & 0.1585 & 0.0784 & 0.0000 & 0.2370 \\
2011 & 0.1669 & 0.1060 & 0.0235 & 0.2964 \\
2012 & 0.2085 & 0.1468 & 0.0576 & 0.4129 \\
2013 & 0.1791 & 0.1728 & 0.0964 & 0.4482 \\
2014 & 0.1612 & 0.1859 & 0.1429 & 0.4900 \\
2015 & 0.2236 & 0.1825 & 0.1748 & 0.5809 \\
2016 & 0.2302 & 0.2154 & 0.2013 & 0.6469 \\
2017 & 0.2236 & 0.2036 & 0.2320 & 0.6591 \\
2018 & 0.2248 & 0.2283 & 0.2741 & 0.7272 \\
2019 & 0.2279 & 0.2911 & 0.3226 & 0.8416 \\
\hline
\end{tabular}

Table 2 shows that green development of agriculture in Guangxi has changed tremendously in the past 10 years, and the development speed is steadily increasing, showing a linear upward trend. The comprehensive score of Guangxi's agricultural green development increased from 0.2370 in 2010 to 0.8416 in 2019, it has increased by 0.6046 in the past 10 years, with a year-onyear growth rate of $255 \%$ and an average annual growth of 0.0672 . In the 2012-2014 and 20162017 phases, the development speed was slow, and the 2011-2012, 2014-2016 and 2017-2018 phases developed faster. Especially since 2017, the state has promoted the green development of agriculture, many policies for benefiting agriculture have been issued. In addition, Guangxi has a unique climate, geographical advantages, and great development potential in the future. 
Descriptive trend analysis

According to the scores of green production, economic benefits and living standards in Table2, to analyze the direction of changes in the green development of agriculture in Guangxi, this paper selects the scores in 2010, 2015 and 2019. It draws them as shown in Figure 1.

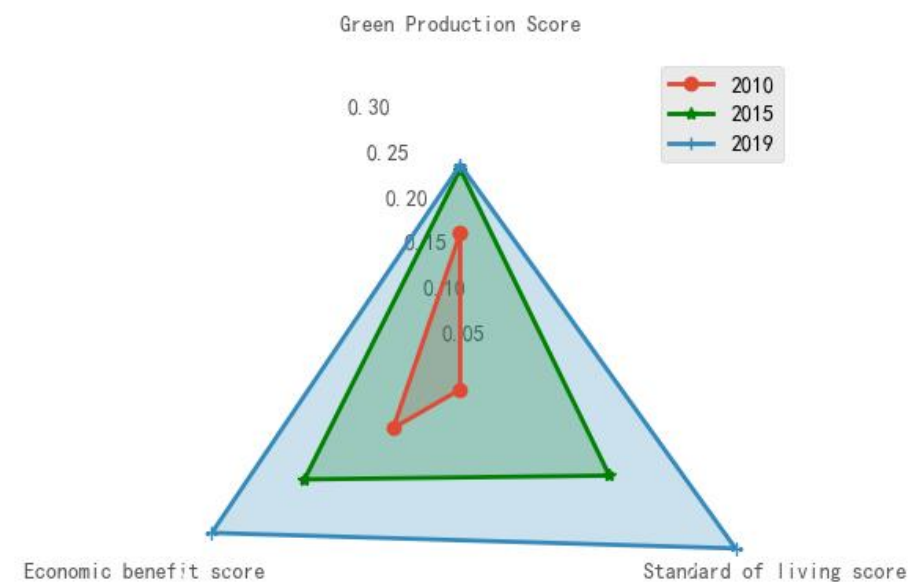

Figure 1. Trends of response layer scores in 2010, 2015 and 2019

Figure 1 reflects the direction of changes in the green development of agriculture in Guangxi over the past 10 years. In 2010, the highest green production score was 0.1585 , while the lowest living standard score was close to 0 . At this time, rural economic life was still low, and overall development was unbalanced. By 2015, green production, economic benefits and living standards have improved, and living standards have improved the fastest. Compared with 2010, it has increased by 0.0651 and the growth rate is $41.09 \%$. At this time, green production, economic benefits, and living standards have achieved balanced development. However, by 2019, the growth rate of green production score will slow down or even stagnate, indicating that Guangxi's agricultural green development has problems with green production. The living standard score has reached the highest score of 0.2279 , an increase of 0.1478 compared to 2015 , a growth rate at $84.56 \%$, the overall development is gradually unbalanced, and it is tilted towards the development of an agricultural green economy.

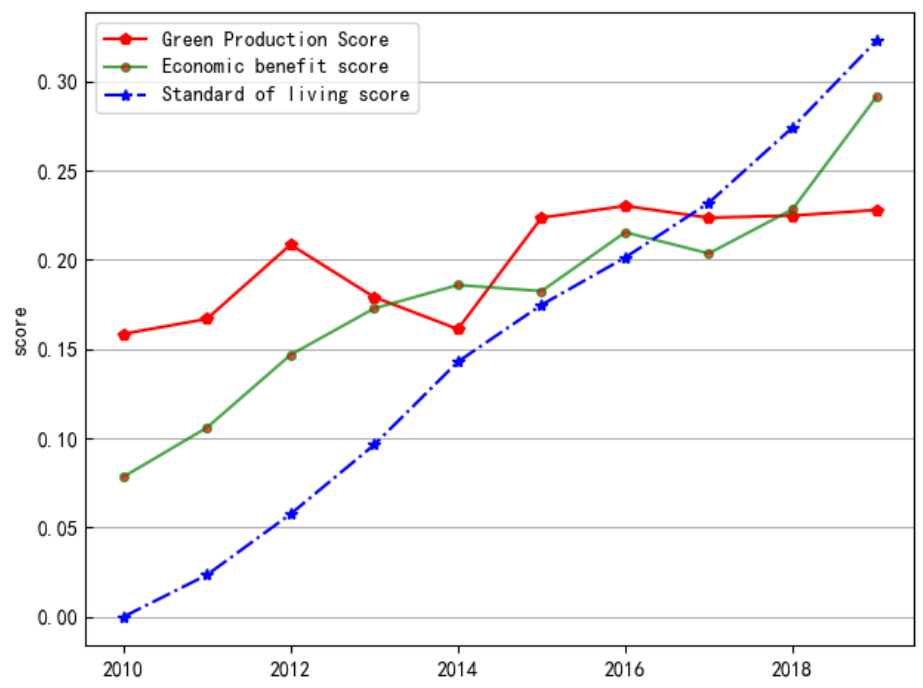

Figure 2. Score of green agricultural development 
Figure 2 reflects the green production, economic benefits, and life of Guangxi's agricultural green development from 2010 to 2019.The development trend of the level, the reasons for its development are explored, and the following results are obtained.

First, Guangxi's agricultural green development has improved its green production score, but the improvement is small. After 2015, green production has shown a stagnant state of development. Analyze the specific reasons for the development of green production: The total power of mechanization per unit area, sewage treatment rate and deep forest coverage rate in Guangxi's agricultural green production are slowly increasing, indicating that the efficiency of green agricultural production is gradually accelerating, and the environmental protection is paid attention to while agricultural production. However, the use intensity scores of chemical fertilizers and irrigation water show a large fluctuating downward trend, leading to a steady decline in the overall green product development. It reflects that there is still a lack of effective utilization of resources in Guangxi agricultural green production, and the utilization efficiency of resources needs to be improved.

Second, the score of economic benefits of green agricultural development in Guangxi shows an increasing trend, which develops slowly from 2012 to 2017, and then increases sharply after 2017. This paper analyzes the specific reasons for the development of economic benefits: as the social and economic development is getting better and better, the economic source of agricultural production is also getting better and better, the demand for agricultural products is increasing, and the scores of gross agricultural output value per unit area and per-capita agricultural output value are increasing, but with the proportion of the secondary industry and the tertiary industry in GDP increasing, the index score of the proportion of agricultural output value in GDP has decreased year by year. However, on the whole, the economic benefits of green agricultural output have been greatly improved. In order to better improve Guangxi's agricultural economy, the output efficiency and quality of agricultural products can be further improved.

Third, Guangxi's agricultural green development has always maintained a linear upward trend in the scores of living standards. Analyze the reasons for the specific growth and development at the level of living standards: rural residents' per capita disposable income, per capita consumption expenditure, and per capita housing area scores have all approached 0 from 2010 and have increased to $0.1123,0.1074$, and 0.1030 in 2019 , respectively. The increase is large, indicating that the economic benefits brought by the green development of agriculture in Guangxi or the influence of other factors have made the quality of life of Guangxi farmers have a qualitative leap, and the revitalization of rural areas driven by green development of agriculture is gradually being realized.

\section{Analysis of agricultural green development space in 14 cities in Guangxi}

\section{Calculation results}

This paper collects the index data of Guangxi in 2019, estimates the agricultural green development level of 14 cities in Guangxi in 2019, and analyzes their differences in green agricultural development. Establish the initial data matrix $X^{\prime}=\left[\mathrm{x}_{\mathrm{ij}}^{\prime}\right]_{14 \times 12}$, and use the above entropy method formula (2-1) to (2-5) to calculate the weight of green agricultural development of 14 cities in Guangxi in 2019. The calculation results are shown in Table 3. 
Table 3. The calculation results of the weights of agricultural green development indicators in the 14 cities of Guangxi in 2019

\begin{tabular}{cccccc}
\hline $\begin{array}{c}\text { Response } \\
\text { layer }\end{array}$ & $\begin{array}{c}\text { Indicator } \\
\text { variable }\end{array}$ & $e_{j}$ & $g_{j}$ & \multicolumn{2}{c}{$w_{j}$} \\
\hline Green & $X_{1}$ & 0.9694 & 0.0306 & 0.0356 & 0.3609 \\
production & $X_{2}$ & 0.9663 & 0.0337 & 0.0394 & \\
& $X_{3}$ & 0.8579 & 0.1421 & 0.1658 & \\
& $X_{4}$ & 0.9526 & 0.0474 & 0.0553 & \\
Economic & $X_{5}$ & 0.9445 & 0.0555 & 0.0648 & \\
benefit & $X_{6}$ & 0.9320 & 0.0680 & 0.0793 & 0.4210 \\
& $X_{7}$ & 0.9099 & 0.0901 & 0.1051 & \\
Standard of & $X_{8}$ & 0.8975 & 0.1025 & 0.1196 & \\
living & $X_{9}$ & 0.8997 & 0.1003 & 0.1170 & \multirow{2}{*}{0.2181} \\
& $X_{10}$ & 0.9523 & 0.0477 & 0.0557 & \\
\hline
\end{tabular}

According to the matrix $X^{\prime}=\left[x^{\prime}{ }_{i j}\right]_{14 \times 12}$ calculated by the entropy method, use formula (2-6) to perform index weight weighting calculation to obtain the comprehensive scores of agricultural green development and response layer scores of the 14 cities in Guangxi in 2019, and rank them to obtain comprehensive data.

Table 4. Score and ranking of green agricultural development in 14 cities of Guangxi in 2011

\begin{tabular}{|c|c|c|c|c|c|c|c|c|}
\hline \multirow{2}{*}{ City } & \multicolumn{2}{|c|}{$\begin{array}{c}\text { Green } \\
\text { production }\end{array}$} & \multicolumn{2}{|c|}{ Economic benefit } & \multicolumn{2}{|c|}{ Standard of living } & \multicolumn{2}{|c|}{$\begin{array}{c}\text { Comprehensive } \\
\text { development }\end{array}$} \\
\hline & Score & Rank & Score & Rank & Score & Rank & Score & Rank \\
\hline Nanning & 0.1490 & 10 & 0.2376 & 3 & 0.1671 & 1 & 0.5537 & 4 \\
\hline Liuzhou & 0.1847 & 8 & 0.1954 & 8 & 0.1302 & 6 & 0.5103 & 6 \\
\hline Guilin & 0.2776 & 3 & 0.3622 & 1 & 0.1428 & 5 & 0.7826 & 1 \\
\hline Wuzhou & 0.1568 & 12 & 0.1660 & 9 & 0.0839 & 10 & 0.4067 & 12 \\
\hline North Sea & 0.2762 & 2 & 0.0965 & 12 & 0.1435 & 4 & 0.5161 & 5 \\
\hline Fangchenggang & 0.2262 & 6 & 0.0699 & 13 & 0.1579 & 3 & 0.4540 & 9 \\
\hline Qinzhou & 0.1416 & 11 & 0.2104 & 6 & 0.0810 & 11 & 0.4330 & 11 \\
\hline Guigang & 0.2961 & 1 & 0.1537 & 10 & 0.1179 & 7 & 0.5677 & 3 \\
\hline Yulin & 0.2557 & 4 & 0.2036 & 7 & 0.1639 & 2 & 0.6233 & 2 \\
\hline Baise & 0.1964 & 7 & 0.1374 & 11 & 0.0481 & 13 & 0.3819 & 13 \\
\hline Hezhou & 0.1634 & 9 & 0.2160 & 4 & 0.1047 & 9 & 0.4841 & 7 \\
\hline Hechi & 0.2269 & 5 & 0.0461 & 14 & 0.0412 & 14 & 0.3143 & 14 \\
\hline Laibin & 0.1059 & 14 & 0.2134 & 5 & 0.1159 & 8 & 0.4352 & 10 \\
\hline Chongzuo & 0.1260 & 13 & 0.2676 & 2 & 0.0782 & 12 & 0.4719 & 8 \\
\hline
\end{tabular}

As shown in Table 4, the comprehensive score of Guilin's agricultural green development is 0.7826, Yulin's score is 0.6233. Nanning, Liuzhou, Beihai and Guigang have scores of 0.5-0.6. Wuzhou, Fangchenggang, Qinzhou, Hezhou, Laibin and Chongzuo have the scores of 0.4-0.5. Baise and Hechi have scores of 0.3-0.4.

In 2019, Guilin, Yulin, Guigang, Nanning and Beihai are the top five cities in terms of agricultural green development level. Liuzhou, Chongzuo, Hezhou, Laibin and Fangchenggang are the middle-level cities. Qinzhou, Baise, Wuzhou and Hechi are the last four cities in terms of green agricultural development. 


\section{Spatial distribution characteristics}

In order to better compare the regional differences of the green development of agriculture in Guangxi, this paper uses the standard difference classification method to classify it. The standard difference method is to take the mean $\mathrm{M}$ as the center and the standard deviation $\mathrm{B}$ as the interval to divide the score range into four intervals: $(0, M-B],(M-B, M],(M, M+B],(M+B, 1)$, and define these four intervals as excellent development, good development, average development, and poor development. The mean, variance and interval of green production, economic benefits, living standards and comprehensive scores of agricultural green development are obtained by calculation.

Table 5. grading table of agricultural green development level in Guangxi

\begin{tabular}{ccccccc}
\hline $\begin{array}{c}\text { Grading } \\
\text { standard }\end{array}$ & $\mathrm{M}$ & $\mathrm{B}$ & $(0, \mathrm{M}-\mathrm{B}]$ & $(\mathrm{M}-\mathrm{B}, \mathrm{M}]$ & $(\mathrm{M}, \mathrm{M}+\mathrm{B}]$ & $(\mathrm{M}+\mathrm{B}, 1)$ \\
\hline $\begin{array}{c}\text { Green } \\
\text { production } \\
\text { economic }\end{array}$ & 0.1988 & 0.0616 & $(0,0.1372]$ & $(0.1372,0.1988]$ & $(0.1988,0.2604]$ & $(0.2604,1)$ \\
$\begin{array}{c}\text { performance } \\
\text { standard of } \\
\text { living }\end{array}$ & 0.1840 & 0.0822 & $(0,0.1018]$ & $(0.1018,0.1840]$ & $(0.1840,0.2662]$ & $(0.2662,1)$ \\
$\begin{array}{c}\text { comprehensive } \\
\text { score }\end{array}$ & 0.4953 & 0.1149 & $(0,0.3804]$ & $(0.3804,0.4953]$ & $(0.4953,0.6102]$ & $(0.6102,1)$ \\
\hline
\end{tabular}

As shown in Table 5 According to the classification standards, the agricultural green development levels of 14 cities in Guangxi in 2019 are classified, and the results are shown in Table 6 and Table 7.

Table 6. Classification of agricultural green development levels in 14 cities in Guangxi in 2019

\begin{tabular}{|c|c|c|}
\hline Level & Green production & Economic benefit \\
\hline $\begin{array}{c}\text { Excellent } \\
\text { development }\end{array}$ & Guilin、Beihai、Guigang & Guilin、Chongzuo \\
\hline Well developed & Fangchenggang、Yulin、Hechi & $\begin{array}{c}\text { Nanning、Liuzhou、Qinzhou、 } \\
\text { Yulin、Hezhou、Laibin }\end{array}$ \\
\hline General development & $\begin{array}{c}\text { Nanning、Liuzhou、Wuzhou、 } \\
\text { Qinzhou、Baise、Hezhou }\end{array}$ & Wuzhou、Guigang、Baise \\
\hline Poor development & Laibin、Chongzuo & Beihai、Fangchenggang、Hechi \\
\hline
\end{tabular}

Table 7. Classification of agricultural green development levels in 14 cities in Guangxi in 2019

\begin{tabular}{|c|c|c|}
\hline Level & Living of standard & Synthesis \\
\hline $\begin{array}{c}\text { Excellent } \\
\text { development }\end{array}$ & Nanning、 Fangchenggang、Yulin & Guilin、Yulin \\
\hline Well developed & $\begin{array}{c}\text { Liuzhou、Guilin、Beihai、Guigang } \\
\text { Laibin }\end{array}$ & $\begin{array}{c}\text { Nanning、 Liuzhou、Beihai、 } \\
\text { Guigang }\end{array}$ \\
\hline General development & $\begin{array}{c}\text { Wuzhou、 Qinzhou、Hezhou、 } \\
\text { Chongzuo }\end{array}$ & $\begin{array}{c}\text { Wuzhou、Fangchenggang、 } \\
\text { Qinzhou、Baise、Hezhou、 } \\
\text { Laibin、Chongzuo }\end{array}$ \\
\hline Poor development & Baise、Hechi & Hechi \\
\hline
\end{tabular}

Combining Table 4, Table 6, and Table 7, it can be seen that the 14 cities in Guangxi have significant differences in the comprehensive scores of green agricultural development. Guilin and 
Yulin are well-developed cities, Nanning, Liuzhou, Beihai, and Guigang are well developed, Wuzhou, Fangchenggang, Qinzhou, Baise, Hezhou Laibin, Chongzuo are generally developed, and Hechi is poorly developed.

\section{Conclusion}

From 2010 to 2019, the overall level of green agricultural development in Guangxi has been greatly improved, showing a linear growth trend. There have been improvements in green production, economic benefits and living standards, among which economic benefits and living standards have improved the most. In contrast, the development of green production has been stagnant. From spatial distribution characteristics, the cities with the best green agricultural development are Guilin and Yulin, while the cities with the poorer development are Hechi. Because of the above situation, the following suggestions are given.

First, in the green development of agriculture, Guangxi still has many deficiencies, especially in green production. We should increase the investment in science and technology and assign more agricultural science and technology personnel to help and guide farmers, such as helping farmers to establish a scientific irrigation system, making better use of agricultural medicine, fertilizer, agricultural film and other resources, so as to improve the utilization rate of resources and promote the green production of agriculture; In addition, we should pay more attention to agricultural production, increase agricultural capital investment, formulate more local policies to benefit farmers, and improve farmers' enthusiasm for production, so as to increase agricultural production and speed up the development of agricultural economy.

Second, in terms of regional differences, due to the great difference of green agricultural development between the East and the west, there is no linkage effect between the regions. Therefore, Guangxi should pay more attention to the green agricultural production in the west to realize the coordinated development of the region, encourage the cities with good agricultural green development to drive the development of the surrounding cities, and realize the improvement of the overall green development level. In addition, we should overcome the disadvantages and develop the advantages. Due to the great differences in geographical conditions, there are many mountains in the western region, so we should make use of the advantages of the mountains, learn more from the planting methods of provinces and cities with good agricultural development, plant suitable agricultural products, and increase the utilization rate of land; There are many kinds of agricultural products in Guangxi, so we should strengthen the propaganda of agricultural products, encourage and help farmers to adopt e-commerce sales mode and expand sales channels; Most of the rural areas in Western Guangxi have inconvenient transportation, so we should strengthen the construction of rural roads, which is not only conducive to the production and sales of agricultural products, but also improves the living standards of farmers.

\section{Acknowledgments}

I would like to extend my deep gratitude to all those who have offered practical, cordial and selfless support in writing this thesis. My deepest gratitude is first to professor Zhang, my mentor, for his constant encouragement and guidance. Without his usual and enlightening guidance, this paper would not have been in its present form. Second, I would like to express my heartfelt thanks to my senior Chen, who has led me to write and modify my paper. Without his help, I don't know how to grasp the writing logic and ideas of the article. Finally, I 
thank my parents for their continued support and encouragement.

\section{References}

Chenghao, Q. (2017). Research on the evaluation of China's agricultural green development level in the economic transition period based on entropy. National Prices, 11, 16-19.

Jianjie, Z., \& Shilei, C. (2020). The construction and illustration of China's agricultural green development index system. China Ecological Agriculture Journal of Industry and Commerce, 28(8): 1113-1126.

Lina, Y., \& Guiying, G. (2018). Research on measurement and influencing factors of green development level of agriculture in Ningxia. Journal of Agricultural Sciences, 1. Available at: https://en.cnki.com.cn/Article_en/CJFDTotal-LXLX201801001.htm.

Lockeretz, W. (1989). Problems in evaluating the economics of ecological agriculture. Agriculture, ecosystems \& environment, 27(1-4), 67-75.

Saimei, J. (2019). Evaluation of China's provincial agricultural green development level and regional differences. Search, 2, 89-95.

Yao, Z., Dongning, L., \& Yong, M. (2020). Construction and application of Shaanxi agricultural green development evaluation system from the perspective of rural revitalization use. Liaoning Agricultural Sciences, 6, 12-17.

Zhuangli, L., \& Jing, T. (2016). The construction of the evaluation index system of the development level of Guangxi's green agriculture. Agriculture Network Information, 11, 12-15. 